\title{
Greves no Estado Novo: um processo de memória em disputa1
}

\author{
Strokes in Estado Novo: a memory dispute process
}

\section{Fatima Gabriela Soares de Azevedo*}

\begin{abstract}
RESUMO: A presente pesquisa analisa greves no Brasil entre 1937 e 1945. O objetivo é compreender se, e como, essa vivência política sobreviveu entre os vencidos, apesar do processo de apagamento levado a cabo pelo Estado Novo e corroborado por distintas correntes historiográficas. A legislação grevista foi alterada na década de 1930 para proibir o seu exercício, sendo endurecida principalmente a partir de 1935 e definitivamente em 1937. Contudo, a instrumentalização da greve para a reivindicação de direitos, melhores condições de trabalho e mesmo para oposição política pode ser comprovada. A comparação entre as fontes que mostram episódios grevistas, como periódicos disponíveis na Hemeroteca Digital da Biblioteca Nacional, com doutrina e propaganda do governo, que afirmam a sua inexistência, revelam um processo de disputa de memória. A memória do movimento dos trabalhadores e trabalhadoras do Brasil fica incompleta quando alguns períodos são estudados sob a perspectiva do silenciamento. Por meio de abordagem benjaminiana, o objeto é trabalhado a partir da problematização da necessidade e justificativa da narrativa estatal de negar a greve em seu contexto histórico. Uma vez explicitado o potencial revolucionário grevista, exemplos são analisados para rever o alegado hiato do protagonismo operário no Estado Novo, a partir da relação entre memória, direito e política.

Palavras-chave: Greve; Estado Novo; Walter Benjamin; Disputa de memória.
\end{abstract}

ABSTRACT: The present research analyzes strikes in Brazil between 1937 and 1945. The objective is to understand if and how this political experience survived among the defeated, despite the process of erasure carried out by the Estado Novo and corroborated by historiography. The strike legislation was changed in the 1930s to prohibit its exercise, especially from 1935 to 1937. However, the instrumentalization of the strike to claim rights, better working conditions and even for political opposition can be proven. The comparison between the sources that reveal striking episodes (newspapers avaiable at Hemeroteca Digital of Biblioteca Nacional) with government doctrine and propaganda, which affirm its inexistence reveals a process of memory dispute. The memory of the Brazilian workers' movement is incomplete when some periods are studied from the perspective of silencing. Through a Benjaminian approach, the object is observed from the problematization of the need and justification of the state initiative to deny the strikes in its historical context. Once the striking revolutionary potential was made explicit, examples are analyzed to review the alleged hiatus of workers' protagonism in the Estado Novo, owing to the relationship between memory, law and politics.

Keywords: Legal history; Strike; Estado Novo; Memory dispute process.

\section{INTRODUÇÃO}

Investigar as greves do Estado Novo importa em retomar momentos da luta dos trabalha-

\footnotetext{
1 Esta pesquisa não recebeu financiamento.

*Doutoranda em Teoria e Filosofia do Direito (UERJ). mestre em Direito Constitucional e Teoria do Estado (PUC-Rio) Graduada em História (licenciatura e bacharelado) pela UNIRIO. E-mail: gabyfsa@gmail.com
} 
dores desde 1930 para pensar sua relação com esse instrumento, como o poder executivo lidou com os episódios grevistas no período, bem como os debates quando da elaboração da Carta Política de 1934 sobre o tema. A constituinte de 1933 é singular na história constitucional brasileira, marcadamente pela representação classista ${ }^{2}$ de eleição indireta, que permitiu, em temas como a greve, a observação do pensamento político e dos interesses dos trabalhadores e patrões de forma mais direta (CABRAL, 2010). A greve era exercida e reconhecida como direito durante a primeira República (SIQUEIRA; AZEVEDO, 2013). Não se pode dizer que até a metade da década de 1930 elas tenham deixado de ocorrer, ao contrário, consolidaram-se como instrumento político um cenário de ascensão da luta antifascista (MATTOS, 2009) (ROMANI,2012).

Autores contemporâneos que se propõem a falar de alguma forma sobre a história da classe trabalhadora brasileira citam diversas greves na República (e até demonstram suas origens em associações que se formam ainda no Império), que são preteridas no período 1937-1945. Ou seja, para diversas abordagens historiográficas, de conservadores a trabalhistas, há um hiato na narrativa sobre a greve entre 1937 e 1945, por exemplo, em GOMES,2007; WEFFORT, 1978; VIANNA, 1999.

Se as greves do Estado Novo não estão destacadas nas correntes historiográficas mais tradicionais que abordam o período, não significa que elas não aconteceram. Mas se evidencia, por outro lado, a necessidade de reencontro dos vencidos com essa imagem de seu próprio passado, de sua própria história. Buscar esses episódios e seus vestígios é um tema de memória, uma tarefa para quem pesquise segundo o materialismo histórico. Uma tarefa, aliás, árdua, haja vista a dificuldade de acesso a fontes primárias e a escassez de estudos sobre greves nesse específico período. A iniciativa política dos vencidos, por tão dificultosa que é, deve ter, para o historiador, destaque central. Não é outra a ideia deste trabalho senão reconhecer a resistência, mas mais do que isso, a insurgência pela greve, num momento de profunda e sofisticada exceção, que se desnuda na existência de órgãos de controle como o Departamento de Imprensa e Propaganda - DIP, e o Departamento de Ordem Política e Social -DOPS, além de toda a estrutura de vigilância estatal "regular".

O texto apresenta como principal questão a seguinte: onde estão as greves, instrumento político dos trabalhadores de oposição não só às condições de trabalho, mas também à grande política, sobre as quais resta silente a historiografia brasileira? Metodologicamente, é preciso revirar a história, ir além da superfície e buscar pela narrativa dos vencidos, conforme propõe Walter Benjamin, já que o discurso oficial omite a existência de movimentos proibidos por legislação e perseguidos pelo Estado ditatorial, restando apenas a possibilidade da procura pelos seus vestígios. Nesse sentido, reconstruir a trajetória da greve, que vai de direito a delito na década de 1930, é trabalhar no campo da história do direito, seguindo, contudo, o alerta de Benjamin, para quem, citando Marx e Engels, uma história do direito não existe por si só e não deve ser tratada de forma apartada do mundo [N, 5 a 3] (BENJAMIN, 2009, p. 509). Com essa abordagem, é possível contribuir para a discussão da memória de resistência dos trabalhadores. A perspectiva da história do direito permitirá, pelo cruzamento de variadas fontes (periódicos, legislação e doutrina) e pelo uso de metodologias complementares, o traçado de um quadro do direito praticado e modificado não apenas pelo Estado, mas, no que tange ao instituto da greve, pelos trabalhadores também.

\footnotetext{
2 Para a constituinte de 1933, além da concorrência para o parlamento através de eleições gerais (214 cadeiras), houve também eleição indireta das associações profissionais para ocupar 40 das cadeiras, divididas em 20 para entidades de empregadores e 20 para associações de empregados. A disposição do artigo 142 do Código Eleitoral foi complementada pelos decretos 22.621, de 5 de abril 1933 e 22.653 de 20 de abril de 1933.
} 
$\mathrm{Na}$ contramão da tendência pós-moderna, a pesquisa se constrói a partir da compreensão da importância da grande narrativa e seu caráter não absolutizante. Conforme SALLES:

[Um] quadro histórico geral, totalidade, não quer dizer abstração, esquema, modelo. O historiador conhece sempre o singular, não importa tanto se a vida é de uma pessoa, de uma nação, de uma região, de uma economia mundo, sistema mundo, civilização. No ato de conhecer ele produz, utiliza traduz, no sentido de transpor, de uma situação e linguagem para outras, reproduzindo-os, conceitos e noções históricas gerais (2012, p.226).

Para a compreensão da historicidade dos períodos ditatoriais brasileiros é necessário observar não só a organização política do Estado, mas observar os mecanismos dos quais se utiliza a violência de Estado como forma de forjar o consenso. Com isto não se pretende simplificar a compreensão de diferentes períodos históricos brasileiros, ao contrário, complexificar os entendimentos a partir de práticas e conceitos que se ressignificam. A violência de Estado metropolitana, imperial, da primeira república e de Vargas não representam um continuum, muito menos um esquema de progresso. É necessário historicizar a violência e não naturalizar o conceito para que sirva de categoria explicativa. Aqui se pretende investigar a violência estruturante, que funda e que mantém, e a sua relação com o direito (BENJAMIN, 1986).

A análise das fontes normativas do Estado Novo revela a inscrição da exceção em uma ditadura e o solapamento da viabilidade jurídica da greve e da potência de violência que funda, pela violência que mantém. Dessa análise emerge uma hipótese: a farta produção normativa no sentido de proibição de greve é uma resposta da autoridade do Estado a um fato político, uma ocorrência social. Nesse sentido, é preciso buscar a história além dos livros e leis. Trabalhos de narrativas historiográficas distintas apontam na direção das atividades de movimentos de trabalhadores (e não sindicatos) e de trabalhadores independentes. Com essa hipótese, jornais de grande circulação na capital no período, disponíveis na Hemeroteca Digital da Biblioteca Nacional ${ }^{3}$, como o Correio da Manhã, O Cruzeiro, o Jornal das Moças, o Jornal do Commercio, A Noite, e A Ordem, que tratam de processos do Tribunal de Segurança Nacional, são analisadas e nelas se pode verificar que a greve está presente no dia a dia do período, além da efetiva juridicização da atividade política, como casos de julgamento e condenação pelo mero ato de distribuir panfletos, ou de simplesmente tentar fazêlo.

A memória dos trabalhadores e suas greves no período do Estado Novo deve ser rediscutida, ou seja, os episódios de greve devem ser trazidos à baila e investigados para compreensão mais abrangente da própria história desses atores no período. A memória como direito, como direito humano no tempo presente de modo mais específico, é um recurso para compreensão de narrativas e discursos em embate no Estado Novo, das subjetividades políticas envolvidas nos conflitos, da história do direito brasileiro, da construção política dos períodos ditatoriais do país. O estudo das greves contribui para estudos da identidade da classe trabalhadora brasileira, das suas ações, dos silenciamentos que atravessam sua história.

3 A consulta à Hemeroteca Digital da Biblioteca Nacional pode ser realizada por meio do sítio eletrônico: https://bndigital.bn.gov.br/hemeroteca-digital/ Acesso em: 05 out 2020. 


\section{1) A GREVE NÃO ESTÁ NA LEI E NEM NA DOUTRINA}

A noção de greve se altera durante a década de 1930. A partir de 1935, dispositivos com força de lei, como decretos lei, e a própria Constituição outorgada em 1937 próbem a greve, até então reconhecida político-juridicamente (como mostram os debates da constituinte de 1933). Há bastantes estudos sobre a natureza e a composição do movimento sindical no período do Estado Novo, sobretudo na corrente tradicionalista representada, por exemplo, por Weffort e Werneck Vianna (perspectiva que vê populismo no executivo e peleguismo nos sindicatos) e nos estudos do trabalhismo, a partir dos trabalhos de Ângela de Castro Gomes (que reconhece maior protagonismo das organizações de trabalhadores e nos trabalhadores individualmente nas tensões políticas desenvolvidas entre 1937 e 1945); contudo não se fala em greve. A conclusão lógica a partir das leituras é a de que a repressão do governo autoritário seria tal que liquidaria a possibilidade grevista.

Fonte interessante de pesquisa são os textos de juristas do período, como Estellita Lins, Julio Barata e Helvécio Lopes Xavier (sobre este último o texto de debruçará em específico) nos quais se observa o debate doutrinário. Em artigo publicado na Revista Forense, uma publicação jurídica, em março de 1938, o jurista Helvécio Xavier Lopes apresenta opinião contraditória sobre a greve. Sob o aspecto histórico, o autor destaca que a greve aparece como fato sociológico e fenômeno social no século XIX no bojo do desenvolvimento industrial.

A partir da ideologia do trabalho livre, Lopes observa que há hegemonia patronal no âmbito do trabalho, e que as greves não podem ser vistas como antijurídicas sob nenhuma hipótese. A conquista desse direito teria sido episódio importante do século XIX, que serviu "para traduzir, numa imagem de Cawes, a sanção direta do direito de coligação: a guerra industrial” (LOPES, 1938). Nesse sentido, greves e lock-outs não deveriam existir sem limitações, pois vitórias de qualquer uma das partes destruiria o equilíbrio entre a força de trabalho e os patrões. Como conclusão, estabelece paralelos entre direito de greve e direito de guerra, afirmando que ambas têm a finalidade de limitar a violência nesses episódios sem extirpar suas possibilidades (no caso da greve: proibição de boicote e sabotagem). O direito à greve e o direito à guerra constituiriam o direito do antijurídico. Por outro lado, Estellita Lins (1938) e Julio Barata (1938) não problematizavam a inviabilização da greve no país.

Na observação das leis se destaca a edição de normas que proíbem e impõem sanções gradativamente piores à prática de greve de 1935 a 1943, como o Decreto Lei 38/1935 (artigos 18 e 19); Decreto Legislativo no 6/1935, que emenda a Constituição de 1933; artigo 139 da Constituição de 1937; Decreto Lei 431/1938 (artigos $2^{\circ}$ e $3^{\circ}$; decreto Lei 1237/1939 (artigos 81 a 83); Decreto Lei 1402/1939 (artigos $1^{\circ}, 2^{\circ}, 4^{\circ}$ e 17); Decreto lei 2848/1940 (Código Penal) - artigos 197 a 202; Decreto-Lei no 4.766/ 1942 (artigos $1^{\circ}$ e 33); Decreto-lei n. ${ }^{\circ}$ 5.452/1943 (Consolidação das Leis do Trabalho) - artigos 722 a 725 .

O decreto lei no 38/1935 proíbe a greve efetivamente política, como movimento que se inicie por "motivos estranhos à relação de trabalho", bem como se extingue a possibilidade jurídica da greve no serviço público. Em 1937, a greve aparece na constituição como elemento verdadeiramente odioso, porque é reconhecido seu potencial de fratura na ordem, na harmonia social. Em 1938 as penas para os crimes já expostos em 1935 são aumentadas. Em 1939, numa aceleração do tempo, pretensiosamente controlada pelo Estado, o decreto lei 1237, que regulamenta a Justiça do Trabalho, prevê o tipo penal greve (ao arrepio da tendência de especialização das normas jurídicas). Para fechar o ciclo da dinâmica normativa seria possível ainda falar do Código Penal de 1940 e da 
Consolidação das Leis Trabalhistas de 1943.

A consulta às fontes legislativas do Estado Novo desnuda seu caráter autoritário e evidencia o solapamento da viabilidade jurídica da greve, ao tentar inviabilizar sua potência criadora a partir do uso da violência (que serve para manter o poder no Estado). A exceção brasileira da década de 1930 deve ser lida principalmente a partir da historicidade latina de pensamento sobre o conceito (ROZO, 2011), de sua própria tradição política ${ }^{4}$. Há rupturas e descontinuidades do Estado Novo em relação ao passado político brasileiro, é preciso compreender essa complexidade.

Vargas não precisaria editar uma série de decretos de proibição de greves se não considerasse o perigo, a iminência de seu acontecimento. Essa justificativa, mesmo em período de exceção, tende a se embasar mais na experiência concreta do que em um gosto desarrazoado por um específico tipo penal. Nesse sentido, é preciso aprofundar-se nas camadas da história para descobrir a narrativa dos vencidos que corre subterraneamente, por baixo da história oficial, que só enxerga os sindicatos em conversa com o governo no Estado Novo. Contudo, havia outras organizações, organizações políticas lato sensu e organizações de trabalhadores, clandestinas, mas reais, além das próprias disputas de sindicatos (constituídos segundo as regras vigentes) com o governo. Há historiografia que reconhece tais fatos (MATTOS, 2003, p.22-23).

A farta produção normativa no sentido de proibição de greve é uma resposta de autoridade do Estado a um fato político, uma ocorrência social. Se a greve é tão enfaticamente combatida, seja pelas normas jurídicas seja pela perseguição política nas ruas, cabe a hipótese do reconhecimento, pelo regime de exceção, da potencialidade destituinte da greve. Ou seja, da superação do Estado Novo. Perseguir a greve é perseguir a possibilidade comunista, anarquista, socialista, a unidade antifascista.

\section{2) A GREVE NA LEITURA BENJAMINIANA}

A greve e a excęão, nas leituras de tempo e história de Walter Benjamin, fazem parte da dinâmica dos oprimidos que emerge, na disputa política, da fratura do tempo aberta sob a exceção decretada sem consulta, e que busca romper com a ordem do tempo presente. A exceção em territórios da América Latina deve ser observada segundo sua própria historicidade, de modo que é preciso destacar que embora existam identificações autoritárias em desenvolvimentos teóricos sobre política entre Brasil e Alemanha (país a partir do qual escreve Benjamin) entre 1937 e 1945, a tradição política tem especificidades. No Brasil, a tal altura há uma prática marcada pela herança colonial e do pós-independência, com apenas poucas décadas de separação temporal do fim legal da escravidão. O contexto europeu de emergência do nazifascismo tem outros elementos de explicação. Este aviso inicial não tem o sentido de justificar uma história fragmentada, de reconstruir um único momento em um único lugar, mas de explorar a relação

\footnotetext{
${ }^{4}$ De acordo com a leitura decisionista do constitucionalista alemão Carl Schmitt (2006), seria possível verificar em Vargas, que encarna a figura filosófica do soberano, aquele que faz direito em seus decretos-lei e que decide o que está fora e dentro deste campo jurídico. É o chefe do Estado Novo quem define, em última instância, quem é o inimigo interno em suas políticas e é também quem escolhe a resposta violenta para combater a viabilidade política desse inimigo. Schmitt é parte de um debate de que participa Walter Benjamin na Alemanha sobre Estado, direito e religião. Contudo, uma aplicação sem mediação das especificidades históricas latinas e locais poderia gerar naturalização e não compreensão da política brasileira, especialmente entre 1937 e 1945.
} 
Entre 'estrutura' e 'acontecimento', [em que] a história não é uma convidada: é a condição de possibilidade para reconstruir o modo particular de articulação das determinações; a ferramenta que permite ler tanto o 'acontecimento' como a 'estrutura', em sua forma 'conjuntural', isto é, como 'momento atual' das contradições sociais (PORTANTIERO, 1997, p. 179, APUD SALLES, 2012, p.224).

A greve é, pois, um acontecimento pelo qual se pode compreender a exceção e suas articulações na luta de classes. O elemento fundamental para esta análise da greve pelo uso da exceção deve ser o fragmento "Sobre a crítica do poder como violência", que precisa ser compreendido no momento em que o autor o escreve e respeitando o conjunto de sua obra, que tem inclinações posteriores ao materialismo histórico dialético e não ao anarquismo, que é a orientação do texto em que aparece diálogo com Sorel. Deste autor, Benjamin toma a classificação das greves gerais em greve política, que visaria reforçar o estado e instituir novo direito; e greve revolucionária, que almejaria a destituição do direito e do Estado. Assim, para Benjamin, o primeiro tipo de greve geral é a violenta e a segunda, a greve revolucionária, seria um meio puro, não violenta, não mediatizada, não se dispondo a restabelecer trabalho após pequenas concessões/mudanças (BENJAMIN, 2019, p.73-74). O texto é enigmático e difícil em toda a sua extensão (BUTLER, 2017, p.77). Para uma melhor compreensão do tema no pensamento do autor é importante cotejar o ensaio principalmente com os escritos que resultaram das reflexões do mesmo período: Destino e Caráter (1919) e o fragmento O Capitalismo como Religião (1921), bem como com as teses Sobre o Conceito de História, fragmento que, embora tenha se iniciado no pensamento de Benjamin em 1920, é o último texto por ele escrito, que não estava pronto para publicação à sua morte, e que retoma e finaliza ideias presentes nas discussões de 1920.

Na obra de Walter Benjamin há preocupação com a identificação do direito com a violência, o que se compreende pela discussão exemplificativa da greve geral, que expõe no limite as formas de controle do Estado. O termo alemão gewalt é polissêmico. Nas traduções para o português de Willi Bolle e João Barrento, o termo pode significar força, violência ou poder. Partindo dessa múltipla possibilidade linguística, é possível observar que Benjamin encontra uma ligação politicamente complexa que se revela na relação do direito, sobretudo nos momentos de suspensão da norma, com o poder. Benjamin analisa a guerra e a greve geral como momentos em que a violência apresenta duas formas - a que funda, legitimamente, e a que mantém, pelo poder. O exemplo da greve reforça como, neste momento crítico, o direito se despe de forma e se apresenta violentamente como poder.

A origem mítica do direito e seu destino de falência também são analisados por Benjamin, através da interação entre o divino, o mandamento, a vida nua, a sacralidade da vida nas relações sociais mediadas pelo direito (BENJAMIN, 2019, p. 74-82). A conclusão do texto, se abolicionista (do direito em si) e permissiva à violência no fazer da política ou se sustentadora de algum direito e contraposta à violência (como vê, por exemplo, Judith Butler), permanece em aberto entre os comentadores da obra do alemão.

No entanto, é inequívoco que a contribuição do ensaio para a teoria do direito é radical: o positivismo e o jusnaturalismo, com suas relações de meios e fins, não servem a propósitos de emancipação. Para a leitura mais crítica de Benjamin, o próprio direito, posto e conservado em violência, deverá ser abolido (BENJAMIN, 2019, p.82) ${ }^{5}$. A interpretação minoritária, abolicionista,

\footnotetext{
${ }^{5}$ A crítica do direito de Benjamin se desenvolve em bases distintas da crítica da forma jurídica realizada por Pachukanis. E para Benjamin o direito não se confunde com lei: "A análise crítica do direito proposta por 
é a que mais se encaixa na observação conjunta dos fragmentos do autor. Se o direito é poder/força/violência, especialmente na modernidade, e se sua narrativa dominante se sobrepõe aos testemunhos vencidos (portados por corpos, por vidas) e esquecidos, ele em si não tem lugar no encontro dos sujeitos (AZEVEDO, 2020).

A greve no Estado Novo, pois, chama atenção do governo e do direito e deve ser proibida não somente porque pode alterar a correlação de forças entre patronato e trabalhadores gerando tensões locais, mas fundamentalmente porque nesse momento histórico a greve é carregada de potencialidades de transformação radical, de ruptura. Apagar a greve é apagar rastros de história dos sujeitos que ficam vencidos na história. As greves por melhores condições de trabalho são, em certo sentido, menos importantes que as greves gerais, mas como correr o risco de permitir a primeira e abrir as portas para a segunda quando o mundo experimenta a radicalização da guerra com o avanço nazifascista? Como conter a greve revolucionária diante do exemplo vivo e pulsante da experiência soviética?

Na primeira metade do século XX, à coletividade dos trabalhadores é reconhecida uma legitimidade histórica e política que aparece no direito. Na década de 1920, Benjamin identifica que

O operariado organizado é, hoje em dia, o único sujeito, além do Estado, ao qual se concede o direito à violência. Contra esse ponto de vista, é certo, pode objetar-se que a recusa de agir, a não ação - coisa que, em última instância, a greve é - de modo algum pode ser referida como violência. Foi provavelmente esse fato que facilitou ao poder do Estado a aceitação do direito à greve, quando esta já não podia ser evitada (BENJAMIN, 2019, p.63).

A inevitabilidade da greve levou ao seu reconhecimento. A contenção não foi ideia de Getúlio (embora a proibição seja uma nota de destaque), é o controle da ação grevista que dá o tom de sua previsão legal e nesse sentido se dão as divisões de greves legítimas e legais e ilegítimas e ilegais. Greve aceitável é greve sem violência e por melhoria nas condições de trabalho de um ambiente/categoria em específico. Mas, Benjamin alerta que mesmo quando somente se está parado recusando o trabalho pode ocorrer o momento de violência, inclusive sob a forma da chantagem. Para ele, "do ponto de vista do operariado, que se opõe ao do Estado, o direito à greve corresponde ao direito de exercer a violência para alcançar determinados objetivos" (BENJAMIN, 2019, p.64). A coletividade, a possibilidade de união e potencialização de poder destituinte e criativo da greve é então o que a legislação pretende restringir e o que os trabalhadores pretendem catalisar.

No direito positivo (em contraposição ao direito natural), o poder é histórico e não natural e "busca 'garantir' a natureza justa dos fins pela legitimidade dos meios" (BENJAMIN, 2019, p. 61). No entanto, própria relação entre meios e fins deve ser problematizada. Benjamin faz um paralelo entre greve e guerra no direito, uma comparação que aparece invertida no pensamento do jurista Helvécio Xavier Lopes, para quem a greve e a guerra limitam a violência, citado no item anterior.

Talvez tenhamos antes de dar atenção à surpreendente possibilidade de o interesse do Direito pela monopolização do poder em face da pessoa individual não se explicar pela intenção de garantir os fins de Direito, mas antes o próprio Direito. Trata-se da possibilidade de o poder,

Benjamin está profundamente vinculada à problematização e no questionamento de um regime de historicidade que está no cerne da modernidade capitalista." (VIEIRA, 2016, p.15) 0 positivismo é também alvo da crítica benjaminiana, junto ao historicismo. Não pode haver normatização que normaliza a sequência de memórias conhecidas e acontecimentos comemorados da humanidade. 
quando não cai sob a alçada do respectivo Direito, o ameaçar, não pelos fins que possa ter em vista, mas pela sua simples existência fora do âmbito do Direito (BENJAMIN, 2019, p. 63)

O poder é o que deve ser preservado e permanecer. As suas diferentes manifestações na história buscam, afinal, essa continuidade. No exemplo das polícias é possível observar que conservam diferentes funções do poder e que destoam da aparência da democracia, se assemelhando mais a monarquias em que, a um só tempo, soberanos são chefes do poder legislativo e do poder executivo (BENJAMIN, 2019, p.69). As polícias aparentemente fundam direito pela decisão e mantêm o direito pela sua execução. A fronteira entre normalidade jurídica e excepcionalidade é quase indiscernível na urgência da atuação policial. A sua regra é agir segundo a lei, que lhe faculta agir apesar de seus limites e garantias. As polícias expressam e reforçam poder quando contêm greves, quando decidem como desmobilizar um protesto, quem levar para detenção e prisão. A primeira decisão jurídica e, portanto, política sobre a greve (e a "questão social" e a manifestação de oposição coletiva) é a da polícia.

A greve é uma ameaça ao poder instituído e por isso faz sentido tentar escondê-la e criminalizá-la, potencializando assim, inclusive, o poder discricionário da polícia. A previsibilidade legal da greve é, portanto, um paradoxo do próprio direito, à medida em que ela pode ser um meio de destituição do direito, do poder com que se relaciona, da violência necessária para sua perpetuação. É esse o medo do governo de Getúlio Vargas, que em 1937 proibi a greve no direito e nos jornais.

O paradoxo no direito parece se resolver, mas para a dinâmica factual de disputa do poder permanece. Contudo, nem o direito e nem o mero poder, ambos se usando da violência, tem o condão de extirpar comportamentos e ações. A censura não impede a oposição, bem como a tipificação de diversas condutas humanas, como homicídio e aborto, não impede as práticas. A greve que desaparece da lei não desaparece da história, ainda que seja necessário escavar para encontrar seus rastros.

\section{3) SE AS GREVES EXISTEM NO ESTADO NOVO, ONDE ESTÃO?}

Pesquisas recentes contradizem o silêncio das narrativas historiográficas estabelecidas com uso de fontes acessadas nas últimas duas décadas ${ }^{6}$, como o trabalho de Marcelo Badaró de Mattos (2003, p.22-23), que identifica movimentos grevistas a partir de 1942. Episódios de greve aparecem em fontes como jornais, panfletos, processos do período. As greves estão em toda parte e não deixaram de povoar o imaginário. A observação do aparecimento do termo em jornais no período

\footnotetext{
6 Gustavo Siqueira (2015) em seu texto “Experiências de greve no Estado Novo" faz um apanhado de variadas fontes, como panfletos de organizações políticas, análises de processos do Tribunal de Segurança Nacional, doutrina e dicionários para defender que a greve como ação ocorreu durante o Estado Novo, mas teve contornos, significados e vivências alteradas de acordo com a intencionalidade do governo de promover o sufocamento dessa experiência política. Achados efetivos e/ou rastros substanciais aparecem também nos estudos de AREAS, Luciana Barbosa. Consentimento e resistência: um estudo sobre as relações entre trabalhadores e Estado no Rio de Janeiro (1930 - 1945). Tese de doutorado. Orientador: Claudio Henrique de Moraes Batalha. Campinas: Universidade Estadual de Campinas/IFCH, 2000; PUREZA, Fernando Cauduro. "Os bondes já estão parando": uma reflexão sobre as greves de abril de 1945 em Porto Alegre. Revista Mundos do Trabalho, vol. 2, n. 3, janeiro - julho de 2010, p. 236-260; COSTA, Hélio da. Em busca da memória: comissão de fábrica, partido e sindicato. São Paulo. Ed. Scritta, 1995. Capítulo 1: A luta dos trabalhadores no final do Estado Novo, p. 11-52; KONRAD, Gláucia Vieira Ramos. Os trabalhadores e o Estado Novo no Rio Grande do Sul: um retrato da sociedade e do mundo do trabalho (1937-1945). Campinas: Unicamp, 2006 Tese de Doutorado. p. 137-143; entre outros.
} 
do Estado Novo demonstra como essa presença persiste, apesar da censura e da vedação à prática grevista.

Para a análise de periódicos foi mapeado o acervo da Hemeroteca Digital da Fundação Biblioteca Nacional, acessível de forma livre remotamente. As ferramentas de procura online da Hemeroteca vasculham os arquivos com as palavras desejadas ou buscam somente em uma publicação específica, sempre a partir do recorte temporal decenal desejado. A opção pelo acervo digitalizado da Hemeroteca possibilitou uma avaliação qualitativa (com orientação da interpretação do material derivada dos escritos de Walter Benjamin) e quantitativa. Esta última é interessante em razão dos números encontrados. Há 24.433 ocorrências de "greve" em 161 acervos da Hemeroteca Digital no período 1930-1939 no Rio de Janeiro e há 44.637 ocorrências do termo "greve" (que aparece em diversos sentidos, como se verá a seguir) em 380 acervos entre 1940 e 1949, mostrando a capilaridade da ideia na sociedade. Periódicos voltados para diferentes públicos foram selecionados e observados na disponibilidade da Hemeroteca Digital. Para este trabalho não foram procurados sinônimos e equivalentes com variações como "parede", "grevista", "paradista", "lock out", entre outros ${ }^{7}$.

A análise do Correio da Manhã, do Jornal das Moças, d'A Ordem e do Cruzeiro, jornais aqui destacados em função de sua alta popularidade no período, permite verificar como a greve aparece em publicações com conteúdos específicos (para as mulheres e para os conservadores, por exemplo) e para o grande público. É interessante notar nesses periódicos que as greves na França, na Bolívia, na Inglaterra, na Espanha e em diversos países estrangeiros marcavam presença, mesmo se tratando de publicações menos voltadas a conteúdos de política.

Quando se busca o termo "greve" no Jornal das Moças: Revista Semanal Ilustrada, que circulou no Rio de Janeiro de março de 1914 a dezembro de 1968, há 26 ocorrências da expressão na década 1930-1939 e 15 ocorrências na década seguinte. A publicação semanal, dirigida ao público feminino, trazia ilustrações de moda, dicas de beleza, arte e pintura, curiosidades e propagandas. Em suas páginas, uma imagem de mulher ideal era construída (AZEVEDO, 2016, p.62). Notícias sobre greves aparecem até 1935, mas a maior parte das ocorrências é posterior a esse ano e se observa que o termo está associado a variados assuntos, de propaganda de remédio ("Pílulas Foster" parar curar rins que façam "uma greve de sérias consequências") a curtas histórias em quadrinhos.

Em A ordem, revista católica que circulou no Rio de Janeiro entre as décadas de 1920 e 1970, o número de ocorrências também é de 26 entre 1930 e 1939 e 18 ocorrências entre 1940 e 1949. A publicação faz análises políticas das greves, apresentando diferentes classificações: greve econômica, greve política, greve geral, entre outras. A greve dos transportes no Rio de Janeiro é objeto de análise em uma edição, enquanto em outras a Rerum Novarum, e a relação do cristianismo com os direitos sociais são avaliados. Há também crítica à Rússia e sua revolução - o debate sobre greves em outros países na observação da correlação local de forças entre burguesia e grupos de trabalhadores é tema recorrente. O século XIX é retomado em várias edições para discutir impacto e legado de greves no mundo. É interessante notar que em 1936 o jornal qualifica como "greve parlamentar" episódio da discussão (parlamentar) da política dos interventores.

N'O Cruzeiro a greve aparece 51 vezes de 1930 a 1939 e 99 vezes entre 1940 e 1949. A publicação, dos Diários Associados de Assis Chateaubriand, circula da década de 1920 à década de 1970 e é pioneira das revistas semanais ilustradas em técnicas de impressão e diagramação. O ali-

\footnotetext{
7 Uma pesquisa que envolvesse tais termos nas publicações aqui citadas exigiria esforço de análise mais complexa e completa, cotejando, por exemplo, os jornais com outras fontes, como dicionários de maior circulação no recorte temporal.
} 
nhamento político irregular de Chateaubriand com Getúlio pode ser visto na publicação ao longo de sua vida. Após 1937, o termo greve aparece em histórias e notícias internacionais. Greve pacífica, violenta e greve branca aparecem como distintas formas da experiência grevista. O termo parede, sinônimo no período para greve, está presente nas edições (embora não tenha sido analisado para o presente trabalho). Para todas as notícias, para todas as explicações, a greve serve e está presente, ainda que como greve de sexo e greve de fome.

No Jornal do Commercio são 877 ocorrências entre 1930 e 1939, e 1548 ocorrências entre 1940 e 1949. Em A Noite, 3220 no primeiro decênio em análise e 3576 no seguinte. No Correio da Manhã são 3503 menções à greve entre 1930 e 1939 e entre 1940 e 1949, 3614 ocorrências. Até outubro de 1937 há bastantes notícias sobre greves no país. A partir de 10 de novembro são noticiadas diversas greves fora do Brasil, dos trabalhadores de drogarias de Paris aos professores de escolas particulares de Londres.

Nos primeiros anos do Estado Novo, 1937, 1938, greves no Brasil aparecem em alguma menção a momento anterior, em propagandas de remédio (as pílulas Foster aparecem com frequência), em greves de fome, entre outros usos menos políticos que vão do suplemento feminino ao obituário, passando marcadamente pela seção internacional. Não há praticamente nenhuma semana sem notícia de greve (ainda que em outros países), o que reforça a legitimidade da prática, muito presente no fazer político daquele momento histórico.

É certo que "a ausência de greves publicadas nos jornais de maior acesso, tenha contribuído também para a criação de um 'mito' da ausência de greves no Estado Novo" (SIQUEIRA, 2015, p. 244), se por "ausência de greves publicadas" entenderem-se greves como a experiência política coletiva da paralisação do trabalho. Contudo, é necessário destacar a presença da ideia da greve no imaginário, essa jamais censurada. Há uma pista na análise dos jornais no sentido de que a greve não desaparece, apenas uma parte do que ela é (e pode ser) fica encoberta pela barreira político-legal estabelecida no Estado Novo.

Mas não é correto afirmar que não há greves em sentido estrito nos jornais, o que é necessário destacar é que normalmente elas aparecem no pé da página. Escondida entre uma propaganda da Exposição Nacional do Estado Novo e uma da Fábrica Bangu está a chamada da edição do Correio da Manhã de 19 de janeiro de 1939 que agora se destaca:

Greve promovida por um Sindicato

$\mathrm{O}$ ministro cassou a carta de reconhecimento e comunicou o fato à polícia.

A Inspetoria Regional do Ministério do Trabalho no Espírito Santo comunicou ao sr. Waldemar Falcão, titular da pasta, uma tentativa de greve promovida, no porto de Vitória pelo Sindicato de Alvarengueiros. Tomando conhecimento do fato, o ministro do Trabalho proferiu a seguinte decisão:

"Atendendo a que o sindicato em causa ao invés de, como órgão de colaboração que é do Estado (art. $1^{\circ}$ decreto $n^{\circ}$ 24.694), submeter suas reivindicações à Comissão Mista de Conciliação, preferiu promover uma greve, no porto de Vitória (Estado do Espírito Santo), consoante informa a $12^{\mathrm{a}}$ I. R.:

Atendendo a que desse modo infringiu o art. 139 da Constituição Federal, que considera a greve como 'recurso anti-social, nocivo ao trabalho e ao capital e incompatível com os superiores interesses da produção nacional:

Resolvo tornar sem efeito o despacho proferido no processo D.N.T. 8.924-38, afim de cassar a carta de reconhecimento do Sindicato dos Trabalhadores em Alvarenga do Porto de Vitória. Para os efeitos do art. 36 do decreto 34.694, comunique-se à Chefiatura de Polícia do Espírito Santo o presente despacho." 
No pé da página 9 da edição do dia 16 de janeiro de 1940 do Correio da Manhã, está a notícia abaixo transcrita:

\begin{abstract}
A cessação de trabalho em uma fábrica de Santa Catarina
A interventoria federal do Estado de Santa Catarina submeteu à consideração do ministro do Trabalho o inquérito referente à cessação de trabalho por parte dos operários da Companhia de Mineração e Metalurgia Brasil (Cobrasil), o procedimento na cidade de Laguna pela Delegacia da Ordem Política e Social do Estado.

O ministro Waldemar Falcão, despachando o processo nele exarou o seguinte:

'Atendendo a que, da leitura do relatório do sr. Delegado da Ordem Política e Social do Estado de Santa Catarina, se infere a responsabilidade de diversos membros das diretorias dos Sindicatos dos Operários em Pedras e Metalúrgicos, ambos com sede em Laguna, na deflagração de uma greve entre os referidos operários aumento de salário; atendendo a que, admitiam-se justas as reivindicações pleiteadas pelos grevistas não seria esse o meio de postulá-las, tanto mais quanto a Carta Constitucional de 10 de novembro de 1937, em seu artigo 139-2 ${ }^{\circ}$ parte declara ser a greve recurso anti-social nocivo ao trabalho e ao capital e incompatível com os superiores interesses da produção nacional; resolvo determinar à Inspetoria Regional que providencie sobre o afastamento imediato das diretorias dos mencionados sindicatos, designando um funcionário para proceder a balanço e assumir a direção dos referidos sindicatos até completa normalização. Deste despacho, dê-se conhecimento ao sr. Interventor federal'.
\end{abstract}

Ocorreram greves no Estado Novo, houve noticiamento desses episódios, inclusive com publicização do tratamento dado pelo Estado, na pessoa do Ministro do Trabalho: revogação da carta de autorização para o sindicato ou intervenção nas diretorias dos sindicatos até que pudesse haver "normalização". A normalização só pode significar o alinhamento político, a subsunção da auto-organização dos trabalhadores aos interesses do governo, sem a qual não poderia haver o funcionamento ou somente poderia haver, no caso da fábrica de Laguna, um aparente funcionamento. Entre informações objetivas sobre greves ocorridas aparecem textos de órgãos do Estado (ou mesmo sem publicação de autoria) defendendo que o Brasil tenha proibido greves, mas mantido direitos trabalhistas (antes mesmo da sua Consolidação em 1943), caminhando para uma direção de diálogo e consenso, uma evolução. A problematização dessa aparente harmonia foi objeto de estudo de variadas correntes historiográficas, estando presente nos trabalhos de Ângela de Castro Gomes (2007) e Marcelo Badaró de Mattos (2007), por exemplo. A desnaturalização da relação entre Estado e trabalhadores, considerando a greve, precisa ser complementada com análise de fontes como as aqui destacadas. Através da interpretação dessas fontes, o consenso Estado-sindicatos revela seus limites, como nos exemplos de cassação de autorização ou dissolução de diretoria e intervenção, decisões que eram tomadas em processos e saíam publicadas em jornais, práticas aceitáveis, portanto, pelo Estado e conhecidas pela opinião pública.

Como as notícias destacadas, outras aparecem na pesquisa ao acervo do Correio da Manhã, por exemplo: a paralisação dos estivadores de Santos, noticiada em 28 de abril de 1940, além daquelas que se relacionam a julgamentos do TSN. Pesquisas nos processos-crime de cunho político do período, a exemplo dos disponíveis no fundo do Tribunal de Segurança Nacional do Arquivo Nacional demonstram a criminalização até mesmo de "atos preparatórios" de greve, que apontam que, elas eram tentadas com certa frequência.

Em 29 de junho de 1940, o Correio da Manhã noticiou absolvição de grevistas de Santa Catarina, sublinhou-se a pacificidade da greve. Em 21 de setembro de 1941, o jornal informa que três réus foram também absolvidos, estes acusados de promover greve no Pará em uma companhia. Nada foi dito sobre haver ou não violência no ato, posto que no julgamento não foram encontradas 
provas suficientes de que o trabalho tivesse parado. Por outro lado, em 21 de maio do mesmo ano havia sido noticiada a condenação de Angnello Francisco Gomes a um ano de prisão por haver promovido greves no porto de Santos, sem que nada fosse dito sobre serem as greves pacíficas ou violentas.

Em 4 de agosto de 1939, o Correio da Manhã informou que operários se manifestaram em greve em 2 de janeiro do mesmo ano na Estrada de Ferro de Santa Catharina. Os líderes do movimento grevista foram denunciados, na data da edição, no Tribunal de Segurança Nacional. O Ministro do Trabalho havia entendido que, no episódio em específico, o Sindicato atuou contra a greve e, portanto, somente pessoas deveriam ser perseguidas e eventualmente punidas. Em 13 de setembro de 1939, o mesmo jornal informa que retornou ao Tribunal de Segurança Nacional a precatória para citação dos acusados de promoverem a greve na Estrada de Ferro na cidade de Tubarão. A mobilização teve por motivo atrasos no pagamento dos salários. Os réus foram indiciados pois quatro meses de atrasos não justificariam a desobediência à Constituição e ao Decretolei 431. Em 7 de outubro do mesmo ano, o Correio da Manhã volta a falar do processo e notícia dessa vez que os réus foram absolvidos e, mais do que isso:

O procurador requereu fossem extraídas cópias dos depoimentos e remetidas ao chefe de Policia de Santa Catharina, afim de se apurar se existe crime na demora de fornecimentos de gêneros e de medicamentos aos operários daquela via férrea.

A greve, neste caso, não só ocorreu como também não houve condenação dos réus e nem do sindicato. Mas o que chama a atenção em definitivo é que ela desencadeou apuração de crime por parte do empregador. E a decisão por provocar o Chefe de Polícia partiu do Procurador, em uma sessão de julgamento dos grevistas no Tribunal de Segurança Nacional. A greve serviu ao seu propósito, afinal, mudando a situação dos trabalhadores em relação aos patrões. A proibição da greve, se existisse de fato (e não só de direito), nesse caso naturalizaria uma condição como a escravidão: realização de trabalho não pago ininterruptamente, sem responsabilização em caso de perecimento de quem trabalha.

Para além das possibilidades antevistas nas fontes, a greve está na vida, nos fatos, no cotidiano. É a historicidade - e não a legalidade - da experiência o elemento fundamental para sua compreensão e verificação.

\section{CONSIDERAÇÕES FINAIS}

A pesquisa identificou fontes relatando prisões por atos preparatórios de greve e o efetivo acontecimento de greves em regiões diferentes do país. Assim, se conclui que a falta de investigação mais profunda sobre o tema se tenha devido a uma disputa de memória, até então vencida pela versão oficial, do Estado, contraditada. A sobrevivência da greve como mecanismo de resistência dos trabalhadores, apesar das alterações legais, das tentativas políticas de aniquilação é um dado que precisa compor a história dos trabalhadores e das trabalhadoras durante o Estado Novo brasileiro.

A historiografia usualmente utilizada como referência para o período, referenda, de certo modo, a versão oficial de ausência ou minimização da resistência ao modelo corporativista de organização do mundo do trabalho. Isto aconteceu em trabalhos que usa(ra)m lentes de historiadores 
para observar o direito e o que existe na lei. A proibição e a ausência de fartas comprovações da transgressão viabilizaram que a fonte (legal) fosse acatada sem maiores problemarizações. É princípio do fazer histórico observar que a vida transgride a lei, a lei não subsume a vida (e nem a Justiça do Trabalho subsume a greve, portanto), o que nem mesmo o capitalismo, considerado em sua totalidade, consegue, justamente porque há resistência por parte dos trabalhadores e trabalhadoras.

A crítica do direito de Benjamin é certeira. A relação conceitual entre greve, violência e poder, observável nos mecanismos de exceção sobre a dinâmica grevista, demonstra que o direito não contém a realidade social eficazmente na norma e, em última análise, quando resolve uma situação no calor do momento o faz pela violência. É como age a polícia, competente para criar e conter quando chamada para atuar em episódio grevista. É como age o Ministro do Trabalho - seu poder de cassar sindicatos e dissolver diretorias, em paralelo à persecução penal dos grevistas pelos seus crimes, é violência seguida de violência, permeada de contornos legais. Ou seja, a violência está no direito e dele faz parte, dando-lhe conteúdo explicitamente, como é possível destacar em momentos como a greve.

A greve não deixou de existir na prática porque deixou de existir nos textos (leis, decisões, verbetes), ela permaneceu apesar deles. Assim, este trabalho forneceu um quadro de emergência de insurgência em meio a um pretenso uníssono, uma pretensa linearidade na narrativa histórica de 1937-1945. A alegada evolução no tratamento dado à luta de classes no Brasil pelo Estado Novo (conforme aparece, por exemplo, na coluna Tribuna Jurídica da edição de 15 de fevereiro de 1940 do Correio da Manhã) deveria ser criticada, segundo Benjamin, ainda que produzisse efeitos aparentemente positivos: a interpretação de que a história é construída para uma evolução não decorre da análise das condições materiais em que ela é produzida, da análise da realidade dos vencidos, daqueles que ficaram à parte da narrativa oficial.

No ensaio Teses sobre o conceito de história, Benjamin lança reflexões sobre postulados metodológicos do materialismo histórico, pensando o conceito de tempo não apenas cronológico, mas em sua relação com a injustiça histórica, chegando a afirmar, nas Passagens, ao pensar na construção da pesquisa histórica o seguinte: "Que o objeto da história seja arrancado, por uma explosão, do continuum do curso da história é uma exigência de sua estrutura monadológica" [N 10,3] (BENJAMIN, 2009, p. 517). Nesse sentido, um dos objetivos metodológicos de seu trabalho é "demonstrar um materialismo histórico que aniquilou em si a ideia de progresso" [N 2,2] (2009, p. 502). Esta imagem é fundamental para a compreensão da crítica política de Benjamin: o progresso como doutrina, como crença do século XIX, que sobreviveu em marxistas e liberais, não estancou os horrores do nazifascismo antes da perda de vidas de milhares de seres humanos em câmaras de gás.

As ideias de progresso e evolução permearam as projeções e influenciaram a ação política. O progresso contém catástrofe, e por isso a esperança de que ele pudesse, como força fora da história da humanidade, frear o fascismo não se confirmou. Sob a narrativa do progresso estão as memórias da luta de classes. Os conflitos sociais estão abafados em aparente silêncio, revelado, por exemplo, em monumentos pelas cidades. É preciso tirar imagens e momentos da linearidade narrativa porque a linearidade não explica e explicita os acontecimentos, não preserva a sua totalidade, mas apenas projeta uma versão que encobre a resistência. As leis de proibição de greves encobrem as greves.

O fazer materialista histórico se dá em sentido contrário da evidência da história oficial, compreendendo o processo de disputa de memória subjacente, tomando-a por imperativo categórico e condição de romper a injustiça: "A memória se converte, portanto, em uma atividade her- 
menêutica de visibilização do invisível, em conhecimento e dever - para impedir a repetição, mas, principalmente, para fazer justiça" (AZEVEDO, 2019, p. 126).

Neste trabalho ficou demonstrado que o uso político da greve permaneceu no Estado Novo, tanto no sentido de oposição ao governo, quanto no sentido de luta por direitos, por salários, por melhores condições de trabalho. A greve por direitos, ao ser observada no período do Estado Novo, faz emergir a memória dos seus protagonistas.

A memória possibilita conhecer acontecimentos de modo a reabilitar sujeitos, trazer para o agora aquilo que passou sem reconhecimento, sem status de objeto histórico, ou seja, fazer presença. A memória, portanto, tem condições de trazer vida à história, dar sentido ao presente; nome, rosto e trajetória a indivíduos e a coletividades, a partir do encontro dos seus rastros. A greve como instrumento de luta não tem uma pausa no Estado Novo. É necessário procurá-la na ilegalidade, que não se resume a inquéritos policiais descentralizados no território nacional. Mesmo páginas de jornal de grande circulação como o Correio da Manhã, sob análise da censura do DIP, deixam ver a greve. E ela existiu e existe, como instrumento de efetivação de direitos e de resistência política, apesar dos discursos conservadores, que normalizam sua não existência. A análise das greves leva à problematização de associações das trabalhadoras e dos trabalhadores do Brasil a comportamentos passivos, demonstrando que sua ação política direta não foi pausada.

O direito à memória como direito humano ganhou destaque após a segunda Guerra Mundial. No Brasil, sua maior instrumentalização se deu nos estudos sobre o período ditatorial pós 1964. Contudo, a efetivação do direito à memória como um direito humano transcende à sua própria fixação normativa e enunciação política. Ao acessar períodos anteriores, como o do Estado Novo, se pode verificar, em sentido benjaminiano, como a narrativa do progresso se impôs à história dos vencidos. A memória da greve utilizada como instrumento de luta por direitos sob uma ditadura, ao ser acessada no tempo presente permite tanto melhor compreensão da imagem do passado, como melhor compreensão da potência desses sujeitos políticos.

\section{REFERÊNCIAS}

ALMEIDA, Antônio Figueira de. A Constituição de 10 de novembro de 1937 explicada ao povo. Rio de Janeiro: DIP, 1938.

ARÊAS, Luciana Barbosa. Consentimento e resistência: um estudo sobre as relações entre trabaIhadores e Estado no Rio de Janeiro (1930 - 1945). Tese de doutorado. Orientador: Claudio Henrique de Moraes Batalha. Campinas: Universidade Estadual de Campinas/IFCH, 2000

AZEVEDO, F. G. S. A função social na disputa do direito para as mulheres entre 1910-1934. In: SOARES, JOICE; ZANETTI, J.;TEIXEIRA,K.;. (Org.). Jovens Pesquisadoras: direitos e políticas em debate. Rio de Janeiro: AUTOGRAFIA, 2017. Pp: 45-78.

2019.

Cidade e política: Reforma urbana e exceção no Rio de Janeiro. Rio de Janeiro: Gramma,

A cidade através do olhar metodológico de Benjamin. Dossiê Walter Benjamin e o Direito. Rev. Direito e Práx., Rio de Janeiro, Vol. 11, N. 3, 2020, Pp: 2018-2046.

BARATA, Júlio. O espírito da nova constituição. Rio de Janeiro, 1938.

BENJAMIN, Walter. O anjo da história. $2^{\text {a }}$ ed. Belo Horizonte: Autêntica Editora, 2019.

. Passagens. São Paulo; Belo Horizonte: Imprensa Oficial; Editora da UFMG, 2009.

BUTLER, Judith. Caminhos divergentes: judaicidade e crítica do sionismo. Trad.: Rogério Bettoni.

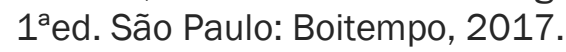

CABRAL, Rafael Lamera. Constituição e sociedade: uma análise sobre a(re)formulação da arquite- 
tura do Estado-Nação na Assembleia Nacional Constituinte de 1933. Dissertação de mestrado. São Carlos: UFSCar, 2011.

COSTA, Hélio da. Em busca da memória: comissão de fábrica, partido e sindicato. São Paulo. Ed. Scritta, 1995. Capítulo 1: A luta dos trabalhadores no final do Estado Novo, p. 11-52

ESTELLITA LINS, Augusto. A nova constituição dos Estados Unidos do Brasil. Rio de Janeiro: José Koffino, 1938.

FAUSTO, Boris. A revolução de 1930: historiografia e história. São Paulo: Companhia das Letras, 1997.

GIANOTI, Vito. História das Lutas dos Trabalhadores no Brasil. Rio de Janeiro: Mauad X, 2007. GOMES, Angela Maria Castro de. A invenção do trabalhismo. $3^{\text {a }}$ Ed. Rio de Janeiro: FGV, 2007 HUNGRIA, Nelson. Compêndio de direito penal. Rio de Janeiro: Jacyntho, 1936.

KONRAD, Gláucia Vieira Ramos. Os trabalhadores e o Estado Novo no Rio Grande do Sul: um retrato da sociedade e do mundo do trabalho (1937-1945). Campinas: Unicamp, 2006 (Tese de Doutorado). p. 137-143

LOPES, Helvécio Xavier. A greve e o "lock-out" como recursos sociais. Revista Forense. Edição de Março de 1938, volume LXXII. Ano XXXV, fascículo 417.

MATTOS, M. B. O sindicalismo brasileiro após 1930. 1. ed. Rio de Janeiro: Jorge Zahar Editor, 2003. PUREZA, Fernando Cauduro. "Os bondes já estão parando": uma reflexão sobre as greves de abril de 1945 em Porto Alegre. Revista Mundos do Trabalho, vol. 2, n. 3, janeiro - julho de 2010, p. 236260.

ROMANI, Carlo. 0 antifascismo italiano no Brasil. As estratégias de anarquistas e comunistas em diferentes momentos das décadas de 1920 e 1930. In: XV ENCONTRO REGIONAL DE HISTÓRIA DA ANPUH-RIO, 2012, São Gonçalo. ANAIS DO XV ENCONTRO REGIONAL DE HISTÓRIA DA ANPUH-RIO. Rio de Janeiro: ANPUH-Rio, 2012. p. 70-70.

ROZO, Antonio Barreto. La generación del estado de sitio en la constituyente de 1991. Bogotá: Universidad de los Andes; Ediciones Uniandes, 2011.

SALLES, R. Gramsci para Historiadores. História da Historiografia, v. 10, p. 211-228, 2012

SILVEIRA SIQUEIRA, Gustavo ; AZEVEDO, F. G. S. . Estado de Direito no Brasil: um debate sobre a Primeira República e o direito de greve. In: Clarice Seixas Duarte ; Daniel Francisco Nagao Menezes. (Org.). 60 Desafios do Direito - Política, Democracia e Direito. 1 ed. São Paulo: Atlas, 2013, v. 3, p. 168-179.

SIQUEIRA, Gustavo Silveira. História do Direito pelos movimentos sociais: cidadania, experiências e antropofagia jurídica nas estradas de ferro. Tese de Doutorado em Direito. UFMG: 2011

VIANNA, Luiz Werneck. Liberalismo e sindicato no Brasil. 4ºd. Belo Horizonte: Ed. da UFMG, 1999. . Caminhos e descaminhos da revolução passiva à brasileira. Revista Dados, Rio de Janeiro, v. 39, n. 3, 1996.

VIEIRA, Rafael Barros. Walter Benjamin: O direito, a política e a ascensão e colapso da República de Weimar (1918/9- 1933) / Rafael Barros Vieira; orientadora: Bethânia de Albuquerque Assy. Rio de Janeiro PUC, Departamento de Direito, 2016.

WEFFORT, Francisco C. O Populismo na política brasileira. Rio de Janeiro: Paz e Terra, 1978.

SCHMITT, Carl. Teologia Política. Belo Horizonte: Del Rey, 2006.

SIQUEIRA, Gustavo Silveira. Experiências de greve no Estado Novo. Revista Direito e Práxis. Rio de Janeiro, [S.I.], v. 6, n. 2, p. 226-253, jun. 2015. ISSN 2179-8966. Disponível em: <https://www.epublicacoes.uerj.br/index.php/revistaceaju/article/view/16527>. Acesso em: 07 jul. 2020. doi:https://doi.org/10.12957/dep.2015.16527.

\section{Fontes primárias analisadas:}

Correio da Manhã, Rio de Janeiro.

o Cruzeiro, Rio de Janeiro. 
Jornal das Moças, Rio de Janeiro.

Jornal do Commercio, Rio de Janeiro.

A Noite, Rio de Janeiro.

A Ordem, Rio de Janeiro. 